\title{
Goal Content Analysis for Middle and High School Students With Disabilities
}

33(3) 132-142

(C) 2010 Hammill Institute on Disabilities

Reprints and permission:

sagepub.com/journalsPermissions.nav

DOI: 10.1 | $77 / 0885728810380230$

http://cdei.sagepub.com

@SAGE

\section{Kendra Williams-Diehm', Susan Palmer', Youngsun Lee ${ }^{3}$, and Heather Schroer ${ }^{4}$}

\begin{abstract}
Goal setting is associated with self-determination and student involvement in learning. Middle and high school students receiving special education services and corresponding special education teachers across six states were asked to name goals on which the students were working. A comparison of the academic, transition, and social goals named by 332 students was conducted to determine differences between groups. Results are reported by school level and the ability levels of students, evaluating both student- and teacher-reported goals from a written evaluation scenario. Relative grade level in school was shown to be a significant factor for content variation but not ability level. Implications for practice and directions for future research are discussed.
\end{abstract}

\section{Keywords}

self-determination, goal setting, high school, middle school

Goal setting is a natural component of adult life displayed through the actions of most successful individuals. People set goals on a daily basis and in almost all facets of life, including work, school, and personal. Interest in goal setting has been around since the 1930s, when the notion of measuring motivation and conscious goals arose (Locke \& Latham, 2002). According to Locke and Latham (2002), a goal is defined as "the object or aim of an action, for example, to attain a specific standard of proficiency, usually within a specific time limit" (p. 705). Goals have been studied in the context of self-determination (Wehmeyer \& Bolding, 1999). Self-determination refers to an individual's perceived ability to make independent choices in his or her own life; the amount of control a person has over his or her decisions could affect the desire to set or achieve goals (Wehmeyer \& Bolding, 1999).

Measurable annual academic and functional goals are a requirement of the Individuals with Disabilities Education Act of 2004. Individualized Education Program (IEP) goals must meet the standards within Section 300.320 of the Individuals with Disabilities Education Act, which mention goals designed to meet the needs of individuals with disabilities, enabling them to be involved in and make progress in the general education curriculum. Thus, IEP goals must contain a description of how a child's progress toward the completion of these annual goals will be measured and the process for reporting progress on annual goals. Transition goals are also a required IEP component for students aged 16 years and older, or 14 years in some states that passed additional legislation to change the age for transition requirements. Therefore, the progress of IEP goals provides guidance for the education and progress of students with disabilities. Although the goals discussed within this article would not be classified as official annual IEP goals, the process of understanding and setting goals and goal accomplishment is critical to both the IEP process and the skill of goal attainment within self-determination.

A definition of self-determination suggested by Wehmeyer (2006) views the construct of self-determination as "volitional actions that enable one to act as the primary causal agent in one's life and to maintain or improve one's quality of life" (p. 117). Volition involves making conscious decisions or being able to make these on the basis of the will of

\footnotetext{
'University of Oklahoma, Norman, OK, USA

${ }^{2}$ University of Kansas, Lawrence, KS, USA

${ }^{3}$ Inha University, Incheon, South Korea

${ }^{4}$ Olathe School District, Olathe, KS, USA
}

Corresponding Author:

Kendra Williams-Diehm, University of Oklahoma, 820 Van Vleet Oval, Norman, OK 73019, USA

Email: klwd@ou.edu 
the individual of focus (Agran \& Wehmeyer, 2008). Four characteristics are displayed by people who are self-determined: (a) acting autonomously, with a minimum of support, if needed; (b) acting in a self-regulated manner, exercising personal control over one's actions; (c) initiating and responding to events in a psychologically empowered manner; and (d) acting in a self-realizing manner, to understand the effects of one's actions on others and the environment in which one lives. Miller and Kelley (1994) saw goal setting as a lifelong skill that is part of self-determination. Goal setting was also listed as one of a number of essential elements by Wehmeyer that can be used instructionally to build capacity for self-determination, which also include choice making, decision making, problem solving, and selfmanagement, to name a few of these elements.

Goal setting provides the ability to empower individuals to achieve their own desires (Wehmeyer, Agran, \& Hughes, 1998). Furthermore, Copeland and Hughes (2002) reviewed 17 studies of goal setting by a total of 284 individuals aged 9 to 54 years to conclude that setting goals, along with other instructional strategies, supported increased performance in the targeted area by children and adults with intellectual disabilities. The specific tasks involved in the articles reviewed for goal setting included assembly and sorting tasks (65\%), work, cleaning, academic, motor, and visual discrimination tasks.

In addition, goal setting has been found to be an effective motivator for students with disabilities (Copeland \& Hughes, 2002; Graham, MacArthur, Schwartz, \& Page-Voth, 1992). For example, students who set academic goals showed greater increases in their performance than students who did not set goals for improvement (Graham et al., 1992). This trend has held constant for students with both learning disabilities and intellectual disabilities (Copeland \& Hughes, 2002; Konrad, Fowler, Walker, Test, \& Wood, 2007; Page-Voth \& Graham, 1999). Page-Voth and Graham (1999) studied the effects of goal setting with students with learning difficulties in the area of writing. When students had specific goals for writing, such as including greater support for statements and elaborating on supporting statements, scores on teacher-administered writing probes increased compared with students who did not set specific goals for improvement (Page-Voth \& Graham, 1999). Students identified as having learning disabilities benefited from self-determination interventions, which also included goal-setting exercises to improve student math skills (Konrad et al., 2007). Similarly, Copeland and Hughes (2002) found that individuals with intellectual disabilities who set goals showed greater gains than peers without goals on targeted tasks. Unfortunately, students with disabilities may have more difficulty developing self-determination skills, including goal setting, compared with students without disabilities (Mithaug, Mithaug, Agran, Martin, \& Wehmeyer, 2003). According to Fuchs et al.
(1997), students who do not learn goal setting on their own should be taught such skills.

\section{Nature of Goals}

Factors that influence goal attainment include the focus and nature of the goal and the individual who sets the goal (Copeland \& Hughes, 2002; Wehmeyer \& Agran, 2005). Goals can often be described as being either process or product focused, depending on the desired outcome (Wehmeyer \& Agran, 2005). Product goals specify an end result, such as graduating from high school or earning specific grades in a course. Process goals, which include items such as turning in all assignments for a class or studying to become a better reader, facilitate reaching product goals. Incremental process goals may be necessary to reach a product goal. In a study of adolescent girls, Zimmerman and Kitsantas (1997) found that those who focused on process goals prior to moving toward product goals had the most success in learning new skills. Individuals who prematurely focused on end results without considering prior steps required to obtain the goal did not show the same level of improvement (Zimmerman \& Kitsantas, 1997).

The orientation of the goal or goal type is another important factor in goal attainment. Examples of goal orientation include task, ability, and a social orientation. Task goals tend to focus on improving in a specific area, such as becoming a better reader, while ability goals tend to focus on how one demonstrates the ability to perform in a given area, often in relation to the performance of others (Urdan \& Maehr, 1995). An example of an ability goal might be to read at a higher level or to become the fastest reader in the class. In addition, Urdan and Maehr (1995) reviewed literature related to goals focusing on social aspects, making the case for social goals to be considered separate from task and ability goals. However, less research has been completed regarding goals targeting social interactions or appropriate behavior in given situations, and a widely used description or procedure addressing the setting of social goals is lacking (Urdan \& Maehr, 1995).

Goal setting requires the ability to think abstractly and focus on long-term outcomes, an ability that typically develops during early adolescence (Shilts, Horowitz, \& Townsend, 2004). Although adolescents may seek independence and resist adult guidance, a significant difference does not appear to exist in the performance of students with intellectual disabilities working on goals chosen by the student or assigned by a researcher or teacher (Copeland \& Hughes, 2002). However, this finding may be specific to the study procedures, participants' intellectual disabilities, or participants' comfort levels in choosing goals for themselves. In other studies, students were assigned goals by teachers or researchers on the basis of reading or writing difficulties (Graham 
et al., 1992; Miller \& Kelley, 1994; Page-Voth \& Graham, 1999). Students in studies in which goals were assigned to them made progress in assigned goals and did not appear to be significantly affected by the individual selecting the goals. Students in the previously mentioned studies made progress toward achieving goals assigned by other people (Graham et al., 1992; Miller \& Kelley, 1994; Page-Voth \& Graham, 1999; Shilts et al., 2004). However, research has also shown benefits for students being more involved in naming their own goals (Wehmeyer, Palmer, Agran, Mithaug, \& Martin, 2000). With practice and continued support, goal setting for students with disabilities can become even more effective (Wehmeyer \& Agran, 2005).

As individuals progress through adolescence, it is reasonable to expect changes in goals because of developmental differences or maturation that might involve more extensive knowledge about the process of goal setting and attainment. For example, high school students tend to set goals that are more differentiated by subject matter than do middle school students (Bong, 2001). Middle school students in the same study were found to be motivated more to demonstrate their ability in a given area with increased feelings of self-efficacy. Adolescent students who had greater feelings of selfefficacy may set ability-oriented goals to show superior capacity in areas in which they feel capable. Many students early in middle school continue to need help with selfregulation, which may lead to difficulties in setting or attaining goals (Berk, 1999). Students in early middle school years are thought to be in Piaget's concrete operational stage, suggesting they have difficulty considering the abstract (Berk, 1999). This may be reflected in goal-setting behavior of younger students, who may set product rather than process goals because of the absolute nature of these types of goals. It may be more logical to a 12 -year-old student to set a goal to pass a class without considering the implications of a plan for the goal, such as completing homework every night, rather than to set process goals necessary to achieve the end result. This may result in setting fewer long-term goals than their older counterparts.

Older adolescents tend to think about the future and set goals that look further ahead, such as attending college after graduating from high school. As adolescents continue to develop, they also become better able to think abstractly (Berk, 1999). Other psychological development concepts, such as the "imaginary audience" (Berk, 1999), may affect students' goals as they progress through adolescence. The idea that an individual is scrutinized by others may lead to setting easily attainable ability-oriented goals to avoid failing in front of others. Because older adolescents usually have increased self-regulation skills (Berk, 1999), they may set more realistic goals and may also examine their progress toward content of their goals periodically. Other implications for enhanced self-regulation include the ability to choose realistic goals and assess possible paths of action.

The purpose of this study was to examine the relationship between the goals identified within an evaluation for self-determination by middle and high school teachers and students. Specifically, we wanted to further investigate if the goals listed by teachers and students on a measure of self-determination differed in content or category of goals on the basis of the grade levels and reported ability levels of the students.

\section{Method}

Participants

Goals were identified by 332 students and their corresponding teachers in secondary schools in six states across the midwestern and southern regions of the United States. Students were asked to identify goals they were currently working on, and teachers were asked to identify goals the students were currently working on. Fifty percent $(n=166)$ of the student participants were middle school or junior high school students, and 50\% $(n=166)$ were high school students. All participants (both students and teachers) consented to be in one of two separate studies focusing on self-determination at either the middle school or the high school level. Initial recruitment efforts in the separate studies targeted schools and students receiving special education services across disability categories who were diverse in terms of ethnicity, location of school setting (urban, suburban, and rural), and socioeconomic level. To obtain the middle school sample, all participants in the middle school study (Lee et al., in press) who provided goals and levels of ability were included in the sample. This resulted in 166 middle school student participants. An equal number of high school students were randomly selected from the separate high school study (Wehmeyer, Palmer, Shogren, WilliamsDiehm, \& Soukup, 2010) using a random number generator. All student participants received special education services at their respective schools.

Demographic information was obtained on all student participants via special education teachers. For the middle school-age sample, ages ranged from 11 to 15 years $(M=$ 13.61 years, $S D=0.8112$ years). The ages of the high school participants ranged from 14.3 to 21.8 years $(M=17.00$ years, $S D=1.51$ years); three participants' ages were not reported. In terms of gender, both the middle school group and high school group had higher numbers of male participants, which is common in special education settings. The three largest ethnic groups were Caucasian, African American, and Hispanic. In terms of disability categories of student participants, the largest categories were as expected: learning disability, intellectual disability, and emotional or behavioral 
Table I. Student Demographic Data $(n=332)$

\begin{tabular}{|c|c|c|}
\hline Characteristic & $\begin{array}{l}\text { Middle school } \\
\text { sample }\end{array}$ & $\begin{array}{l}\text { High school } \\
\text { sample }\end{array}$ \\
\hline Total sample & $166(50.0 \%)$ & $166(50.0 \%)$ \\
\hline \multicolumn{3}{|l|}{ Gender } \\
\hline Male & I I 8 (7I.0\%) & 99 (59.6\%) \\
\hline Female & $48(28.9 \%)$ & $67(40.4 \%)$ \\
\hline \multicolumn{3}{|l|}{ Ethnicity } \\
\hline African American & 35 (21.1\%) & $36(21.7 \%)$ \\
\hline Asian American & $4(2.4 \%)$ & $2(1.2 \%)$ \\
\hline Caucasian & $96(57.8 \%)$ & $96(57.8 .3 \%)$ \\
\hline Hispanic & 28 (16.9\%) & $21(12.7 \%)$ \\
\hline Middle Eastern & I (0.6\%) & $\mathrm{I}(.6 \%)$ \\
\hline Native American & $2(1.2 \%)$ & I $(0.6 \%)$ \\
\hline Other & $0(0 \%)$ & $9(5.4 \%)$ \\
\hline \multicolumn{3}{|l|}{ Disability category } \\
\hline ADD or ADHD & $17(10.2 \%)$ & $5(3.0 \%)$ \\
\hline Autism spectrum disorder & $8(4.8 \%)$ & $12(7.2 \%)$ \\
\hline $\begin{array}{l}\text { Emotional or behavioral } \\
\text { disorder }\end{array}$ & I8 (I0.8\%) & II (6.6\%) \\
\hline Hearing impairment & $0(0 \%)$ & I $(0.6 \%)$ \\
\hline Intellectual disability & $26(15.7 \%)$ & $53(32.9 \%)$ \\
\hline Learning disability & $73(44.0 \%)$ & $66(41.0 \%)$ \\
\hline Other health impairment & $10(6.0 \%)$ & $9(5.4 \%)$ \\
\hline Physical disability & $0(0 \%)$ & 2 ( $1.2 \%)$ \\
\hline $\begin{array}{l}\text { Speech/language } \\
\text { impairment }\end{array}$ & I 3 (7.8\%) & I $(0.6 \%)$ \\
\hline Traumatic brain injury & $0(0 \%)$ & I (0.6\%) \\
\hline Missing data & I (0.6\%) & $5(3.0 \%)$ \\
\hline
\end{tabular}

Note: ADD = attention-deficit disorder; ADHD = attention-deficit/ hyperactivity disorder.

disorder. Complete demographic information is provided in Table 1.

Special education teacher participants provided indicators of ability for student participants on the basis of their performance levels and the support needs of each student. Teachers were asked to provide estimates of the students' cognitive ability by indicating one of two levels: (a) normal ability range (intellectual level at or above an IQ of 70) or (b) ability level below normal (intellectual level below an IQ of 70). Student records did not consistently yield current or valid IQ scores, so indications of intellectual ability were obtained from teachers. It was believed that teachers could provide accurate estimates of performance level and the level of support for students by accessing school records not available to researchers or, in a few cases, through expert opinion. The majority $(65.3 \%[n=218])$ of participating students had teacher-reported levels of ability within normal limits, while $34.7 \%(n=116)$ were reported to have ability levels below normal, showing cognitive disabilities. Furthermore, these two groups of students received services in different settings related to the level of support needed and the corresponding curriculum. For the remainder of this study, the two groups are referred to as normal ability level (reported intellectual level at or above an IQ of 70) and low ability level (reported intellectual level below an IQ of 70). Table 1 outlines the specific disability labels of the participants.

\section{Measures}

For this study, all participants completed the appropriate sections of either the student version or teacher version of the American Institute for Research (AIR) Self-Determination Scale (Wolman, Campeau, Dubois, Mithaug, \& Stolarski, 1994). The AIR scale was created for use with students with and without disabilities to determine actions and feelings related to goal setting at home and at school (Wolman et al., 1994). Acceptable reliability and validity for AIR scores have been reported (Shogren et al., 2008) for the first three sections of the measure, not including the additional openended response section. Carter, Lane, Pierson, and Glaeser (2006) reported a test score stability coefficient after a 3-month test-retest period of .74 and an internal consistency reliability coefficient of .95. Evidence supporting the construct validity of AIR scores has been found (Carter et al., 2006). The first three sections of the AIR self-determination assessment instrument ask individuals to rate their perceived opportunities and support related to setting goals within a self-determination context (student version) or that of the designated student (teacher version). The final section of the measure (Section 4) is open ended and allows both students and teachers to share some current goals being addressed, as well as provide more detail to the forced responses of the first three sections of the scale, but the AIR manual does not describe how to interpret these answers. The three open-ended responses asked within the teacher version were as follows:

Give an example of a goal the student is working on.

What is the student doing to reach this goal?

How is the student doing in reaching this goal?

The three questions for the student version were as follows:

Give an example of a goal you are working on.

What are you doing to reach this goal?

How are you doing in reaching this goal?

The analysis was conducted only on goals provided on Section 4 of the AIR scale.

\section{Procedure}

Section 4 AIR scale response items were entered verbatim into a database for coding purposes using Microsoft Access. 
The database was constructed so that no identifying information, including age, grade, ethnicity, gender, or ability level, could be identified during coding. After examining the goals for themes identified in the literature on goal setting and goal achievement (Johnson \& LaMontagne, 1993; Patton, 1990) and self-determination and goal-setting issues for adolescents with disabilities (Sands \& Doll, 2005; Wehmeyer \& Agran, 2005; Wehmeyer et al., 2007), an initial coding system for goal content was created. The work of Johnson and LaMontagne (1993), as well as that of Pellegrini (1996), was consulted to obtain guidance for creating the original coding system from the qualitative data. The numbers of unique goals provided by students were compiled and indicated in the coding process. As goals were analyzed, the coding system evolved to contain six possible content areas. The initial coding focused on the following four areas: (a) academic, (b) nonacademic, (c) social, and (d) classroom management. As the coding system was refined, two additional categories, long-term academic and longterm nonacademic, were created. Goals classified as long-term included those that would be completed after the current school level. For example, if a student was in middle school, the goal would be completed in high school or following graduation. If a student was in high school, the goal would be completed following graduation. Transitionrelated goals are found under the broad categories of academic and nonacademic goals. Complete definitions of coding descriptions are found in Table 2. Although participants were asked to write a single goal, several participants, including both teachers and students, indicated multiple goals across varying content areas. The researchers decided to maintain all goals reported to provide the maximum depth into the thinking of both students and teachers. This resulted in more goals than participants.

In addition to content area, goals were coded as either product or process under goal category. Product goals were those with tangible ends, such as graduation or achieving a particular grade or accomplishment level. Process goals were more about action steps to achieve product goals or broad indications of improving in certain areas, such as reading, with no specific levels detailed (see Table 2).

Interrater reliability using Cohen's $\kappa$ was applied to both the content and category of goals for students and teachers. Coders could not access information on how other researchers coded items during this process. Twenty-five percent of the goals from each school sample were independently coded by two raters to obtain interrater reliability. As coding progressed, definitions of content areas were refined to ensure an acceptable level of reliability between coders. This included the additional categories long-term academic and long-term nonacademic. All coding was then reviewed to be certain that the refined definitions were included throughout the data set. The resulting interrater reliability for student
Table 2. Goal Analysis Coding Guidelines

\begin{tabular}{|c|c|}
\hline $\begin{array}{l}\text { Coding } \\
\text { number }\end{array}$ & Coding description \\
\hline \multicolumn{2}{|l|}{$\begin{array}{l}\text { Goal } \\
\text { content }\end{array}$} \\
\hline 0 & No goal \\
\hline 1 & $\begin{array}{l}\text { Social goal (involves interactions with adults or } \\
\text { peers) }\end{array}$ \\
\hline 2 & $\begin{array}{l}\text { Academic goal (includes goals related to grades } \\
\text { or specific subject area, work completion, } \\
\text { vocational skills, or school-related activities/ } \\
\text { sports; pertains to goals for current schooling } \\
\text { level of middle or high school; also includes } \\
\text { graduation goals for high school students) }\end{array}$ \\
\hline 3 & $\begin{array}{l}\text { Long-term goal for academics (includes goals } \\
\text { beyond current schooling level, postsecondary } \\
\text { training or education; have clear ties to } \\
\text { academics) }\end{array}$ \\
\hline 4 & $\begin{array}{l}\text { Nonacademic (includes goals not related to } \\
\text { behavior or academics) }\end{array}$ \\
\hline 5 & $\begin{array}{l}\text { Long-term goal for nonacademics (includes goals } \\
\text { related to future employment or achievement } \\
\text { beyond current schooling level; no ties to } \\
\text { academics) }\end{array}$ \\
\hline 6 & $\begin{array}{l}\text { Classroom management goals (relate to following } \\
\text { classroom procedures such as following } \\
\text { directions, being prepared with materials, or } \\
\text { following classroom rules) }\end{array}$ \\
\hline \multicolumn{2}{|l|}{$\begin{array}{l}\text { Goal } \\
\text { category }\end{array}$} \\
\hline 0 & No goal \\
\hline 1 & $\begin{array}{l}\text { Product goal (define end product or outcome, } \\
\text { such as earning certain grades, graduating, etc.) }\end{array}$ \\
\hline 2 & $\begin{array}{l}\text { Process goal (describe actions that would help } \\
\text { with product goals, such as become a better } \\
\text { reader, go to class on time) }\end{array}$ \\
\hline
\end{tabular}

goal content was calculated using Cohen's $\kappa(\kappa=0.87)$, and student goal category agreement was also at an acceptable level $(\kappa=0.82)$. In terms of interrater reliability for teacher goals, Cohen's $\kappa$ for goal content was 0.84 , and that for teacher goal category agreement was 0.88 . Cohen's $\kappa$ values greater than 0.81 are considered excellent, reflecting a high level of agreement (Landis \& Koch, 1977).

\section{Analysis}

Descriptive statistics were obtained to describe the sample and the frequency of goal content and goal category across all reported goals. A Pearson's $\chi^{2}$ test was completed to determine differences in goal content and category by school and ability level for both teacher and student goals. Participants were divided into groups by school level (middle school or high school) and ability level (normal ability or low ability). These groups were then compared across goal 
Table 3. Descriptive Information for Teacher-Reported Goals by School Setting and Ability Level

\begin{tabular}{|c|c|c|c|c|}
\hline \multirow[b]{2}{*}{ Goal } & \multicolumn{2}{|c|}{ School level } & \multicolumn{2}{|c|}{ Ability level } \\
\hline & Middle school $(n=202)$ & High school $(n=207)$ & Low $(n=130)$ & Normal $(n=279)$ \\
\hline \multicolumn{5}{|l|}{ Goal content } \\
\hline No goal reported & 5 & 9 & 1 & 13 \\
\hline Social & II & 17 & 12 & 16 \\
\hline Academic & 145 & 100 & 68 & 177 \\
\hline Long-term academic & 5 & 13 & 6 & 12 \\
\hline Nonacademic & I & 27 & 17 & II \\
\hline Long-term nonacademic & 8 & 25 & 15 & 18 \\
\hline Classroom management & 27 & 16 & II & 32 \\
\hline \multicolumn{5}{|l|}{ Goal category } \\
\hline No goal reported & 5 & 10 & 1 & 14 \\
\hline Product & 66 & 82 & 56 & 92 \\
\hline Process & $13 \mid$ & 115 & 73 & 173 \\
\hline
\end{tabular}

content and category. Multiple goals from the same participant were considered independent goals for analysis purposes, resulting in an unequal total number of goals obtained from an initially equal group of students (middle school compared with high school).

\section{Results}

\section{Teacher-Reported Student Goals}

Several differences were found on the basis of both goal content and goal category for the student-related goals reported by teachers. Table 3 presents descriptive information for teacher goal content by school level and ability level. Significant differences in goal content were found between middle school and high school teacher-reported student goals, $\chi^{2}(6, N=409)=49.91, p=.00$, and ability level, $\chi^{2}(6, N=409)=21.77, p=.01$. The highest number of reported goals for all groups was academic in nature $(71.8 \%$ for middle school, $48.3 \%$ for high school; $52.3 \%$ for low ability, $63.4 \%$ for normal ability). Large discrepancies existed for other categories. For example, $18.4 \%$ of high school teachers reported student goals reflecting long-term goals, whereas only $6.4 \%$ of middle school teachers reported long-term goals for their students. Also, slightly fewer than half $(43.0 \%)$ of teacher-reported goals for low-ability students were not academic in nature. Finally, the classroom management category included more middle school teachers who reported student goals in the area of classroom management than did high school teachers.

Table 3 also presents descriptive information on the basis of the results for teacher-reported student goals and goal category level and ability level. Significant differences were found between goal content and ability level, $\chi^{2}(2, N=409)=$ $7.37, p=.03$. Approximately $65 \%$ of goals from teachers working with students in the normal ability range reported process goals (compared with $35 \%$ product goals). The results were more balanced for teachers working with students with low ability levels (55\% process goals vs. $45 \%$ product goals). However, no significant differences were found on the basis of teacher-named student goal category and school level, $\chi^{2}(2, N=409)=4.38, p=.11$. The majority of both middle school and high school teachers reported student process goals (middle school $66.5 \%$ vs. high school $58.3 \%)$.

\section{Student-Reported Goals}

Many of the results found within the goals directly listed by students mirrored those of goals named by teachers as being goals on which students were working. However, some unique and different results were also found. Table 4 provides descriptive information for student goal content on the basis of school level and ability level. Significant differences in goal content were found between middle school and high school student-reported goals, $\chi^{2}(6, N=387)=19.54$, $p=.03$, but not on the basis of ability level, $\chi^{2}(6, N=387)=$ $11.46, p=.08$. The variation between goal category and ability level approached significance but was not statistically different. Consistent with teacher-reported goals, academics was the largest content area for all subgroups of student goals written by students. However, high school students reported more nonacademic goals $(47.1 \%)$ than did middle school students (37.9\%). Also, more classroom managementrelated goals were again reported within the middle school sample (7.1\%) compared with the high school sample $(1.6 \%)$. Although significance was not found on the basis of ability level, the largest difference occurred between academic goals for the two groups (36.8\% for low-ability students and $48.4 \%$ for normal-ability students).

Table 4 also presents descriptive statistics for student goal category on the basis of school level and ability level. 
Table 4. Descriptive Information for Student-Reported Goals by School Setting and Ability Level

\begin{tabular}{|c|c|c|c|c|}
\hline \multirow[b]{2}{*}{ Goal } & \multicolumn{2}{|c|}{ School level } & \multicolumn{2}{|c|}{ Ability level } \\
\hline & Middle school $(n=198)$ & High school $(n=189)$ & Low $(n=133)$ & Normal $(n=254)$ \\
\hline \multicolumn{5}{|l|}{ Goal content } \\
\hline No goal reported & 1 & 2 & 3 & 0 \\
\hline Social & 1 & 6 & 4 & 3 \\
\hline Academic & 95 & 77 & 49 & 123 \\
\hline Long-term academic & 12 & 12 & 9 & 15 \\
\hline Nonacademic & 35 & 58 & 33 & 60 \\
\hline Long-term nonacademic & 40 & 31 & 29 & 42 \\
\hline Classroom management & 14 & 3 & 6 & 11 \\
\hline \multicolumn{5}{|l|}{ Goal category } \\
\hline No goal reported & 1 & 2 & 3 & 0 \\
\hline Product & 53 & 106 & 59 & 100 \\
\hline Process & 144 & 81 & 71 & 154 \\
\hline
\end{tabular}

Significant differences were found between goal category for both school level, $\chi^{2}(2, N=387)=35.54, p=.00$, and ability level, $\chi^{2}(2, N=387)=7.05, p=.03$, in these goals written by students. Again, more process goals were reported for all groups, with the only exception that high school students reported more product goals. High school students reported product goals at a rate of $56.1 \%$, and $26.8 \%$ of middle school students reported product goals. Within ability level, more low-ability students reported product goals compared with normal-ability students $(44.4 \%$ vs. $39.3 \%)$. This trend also occurred for teacher-reported student goals.

\section{Discussion}

In this study, we sought to analyze and compare teacherreported student goals and student-reported student goals in both goal content and category for middle and high school students with disabilities. Goals were solicited from students receiving special education services in both the middle school and high school settings and from the special education teachers serving those students. The content and category of those goals were analyzed and compared. Areas for analyses included school level (middle school vs. high school) and teacher-reported ability level (within normal ability level and lower ability levels).

Both teacher-reported student goals and student-reported goals resulted in significant differences across school level goal content. Middle school students generally reported a greater percentage of classroom management goals compared with the students in high school, possibly reflecting the more structured environment of middle school or continued emphasis teachers place on class rules (McEwin, Dickinson, \& Jenkins, 1996). High school students reported fewer classroom management goals, shifting attention toward a greater focus on activities necessary for success after high school. Contrary to previous research, middle school students also reported a lower percentage overall of social goals (although not statistically different). Previous findings indicated a greater importance placed on social interactions at the middle school level (Berk, 1999). Urdan and Maehr (1995) suggested that a higher percentage of social goals reported by middle school students may reflect a greater value placed by this age group on peer approval or acceptance. High school teachers and students placed more emphasis on long-term goals compared with middle school teachers and students. This may be reflective of a focus on transition and postsecondary adult outcomes and a shift into future options.

Academic goals were the most frequent goal content area reported by all groups. This finding was consistent with Leondari and Gonida's (2007) discussion of adolescents beginning to develop an understanding of potential as related to achievement. Over time, students may continue to focus on academic interests, either to continue previous success or to increase current performance to reach perceived potential. The high percentage of academic goals reported by all groups potentially reflects the notion that school is a major component of adolescents' lives. Students who are preparing for transition to adulthood from secondary education and expressed long-term goals regarding career choice may also understand the importance of academic achievement for future success and set goals accordingly.

School level was related to goal content, with middle school students setting more academic goals than high school students. This may be due partially to adolescent development. According to Berk (1999), younger adolescents think less abstractly than older peers. A possible outcome of this type of thinking is for students to consider school-related goals when asked about goals in general in a school setting. Middle school students also reported a greater frequency of classroom management goals, perhaps because of a greater 
emphasis on behavior and rule following at the middle school level.

High school students reported significantly more nonacademic goals than did middle school participants, perhaps because they were more involved in the transition process and participation in more adult activities such as part-time employment. For example, numerous high school students' goals centered on finding employment or remaining employed. This may be reflective of more high school students' working or thinking of adult outcome-related goals. This result is consistent with Bong's (2001) finding, suggesting that high school students may be considering postsecondary outcomes, including education and employment. High school students often have commitments outside of school, and goals of this nature would reflect multiple responsibilities. There were no significant differences between school level and the setting of long-term nonacademic goals. This similarity would suggest that both middle and high school students consider long-term goals that are less school related, such as future careers. Teachers, at both the middle and high school levels overwhelmingly indicated academic goals (including long-term academic goals).

In contrast, no overall statistical significance was found in relation to ability level for students, only with the teacherreported student goals. However, ability level appeared to play a small role in goal content for specific areas. Copeland and Hughes (2002) reported that students with intellectual disabilities benefited from goal setting and continued guidance while pursuing goals. The lack of significant differences between the two ability level groups may be due to the greater influence of age in setting goals. Older students may be encouraged to think about different goals in comparison with their middle school peers, as discussed previously, regardless of level of disability, support, or intelligence.

It is worth noting that students with reported low ability levels at both the high school and middle school levels set a greater percentage of nonacademic goals compared with students with normal ability levels. This could be reflective of a more functional curriculum, focusing on transition and postsecondary outcomes, compared with a traditional academic curriculum. Students in the low-ability group may need more extensive supports and thus experience greater academic challenges as the pace and demands of school increase. Students set more goals in areas in which they feel motivated and confident in their abilities (Bong, 2001). Conversely, if students feel less successful in general or in the area of academics, they may be less likely to set academic goals. This greater feeling of past success could partly explain the greater frequency of academic goals in students with normal ability levels.

Middle school students with lower ability levels specifically reported a greater percentage of long-term academic goals compared with all other groups. One possible explanation for this difference may be that middle school students have begun to focus on the coming high school issues and the transition process, specifically on noncore academic classes through electives. Students in middle school may have identified vocational or employment skills to address at the high school level.

It is important to remember that students with lower ability levels may benefit more from different formats, such as verbal or visual feedback, compared with peers with other disabilities (Copeland \& Hughes, 2002). In Copeland and Hughes's (2002) meta-analysis of goal setting interventions with students with intellectual disabilities, students who received extended instruction on goal-setting strategies were more successful in reaching established goals. Extended attention to goal setting in conjunction with the findings from this study may be helpful in working with students with intellectual disabilities in setting and monitoring appropriate goals. Wehmeyer et al. (2007) wrote that research has begun to document the efficacy of goal setting for people with intellectual disabilities. For example, research on the Self-Determined Learning Model of Instruction (Wehmeyer et al., 2000), which uses a goal-setting format, was successful with middle school students with intellectual disabilities (Palmer, Wehmeyer, Gipson, \& Agran, 2004) and high school students also with more severe disabilities (Agran, Blanchard, \& Wehmeyer, 2000).

Statistical differences were found across teacher-reported goals for ability level and student-reported goals for both school level and ability level. In terms of school level, more students $(41.1 \%)$ reported product goals than did teachers (36.1\%). This was interesting in terms of the difference between student and teacher thinking. Teachers often wrote a goal of "improving reading ability," which resulted in a process goal. A student wrote the goal of "reading at 8th grade level," which resulted in a product goal, because the end outcome was specified. Other noteworthy differences in terms of goal category were noted with high school students. More high school students reported product-oriented goals, because of the need to graduate and other high school completion events. Teachers, on the other hand, reported more process goals $(55.6 \%$ teacher-reported process goals vs. $42.9 \%$ student-reported process goals). This could be an indication of a focus on benchmarks and other short-term goals as opposed to the final goal of school completion.

\section{Limitations}

Several limitations are associated with this study. As mentioned previously, participants gathered from the middle and high school levels were part of two separate larger studies focused on a broader issue of self-determination. Students were asked to complete various self-determination assessment instruments, including the AIR scale. Students may 
have written the first goals that came to mind, without any deliberate thought. In addition, several researchers were involved in data collection, and slightly different guidance may have been used to prompt responses to this section. When students asked for further clarification, researchers often modeled an example of a goal, possibly leading students into certain content categories.

Although not intended to be part of this research, another limitation is that student IEPs were not consulted to determine if the goals named by participants, particularly academic and transition-related goals, were actually part of the students' IEPs. Adding an additional depth through student IEPs and transition plans would provide face validity that the named goals were actual parts of the programs students were working on through their educational plans. However, goals need not be officially named in an IEP to provide support for goal attainment skills that support further capacity building within the construct of self-determination.

Another limitation could be the multiple number of goals provided by various respondents. Although the directions indicated to provide a single goal, many participants, both teachers and students, provided multiple goals. The use of additional goals may show a hierarchy in thinking among the participants. We did not distinguish goals on the basis of the order they were listed, and as previously mentioned, we made a deliberate decision to include all goals provided.

Finally, because the random selection of participants was not possible in this study, the representativeness of the sample is unknown. Once a school district agreed to participate in the study, teachers were approached to become research partners. All students within any teacher's class were provided consent forms to take home to be signed by their parents. The informed consent required in any participation of human subjects reduces the randomness of sample selection. Although we perceived the sample reflected the demographics of the schools and school districts, this was not confirmed.

\section{Suggestions for Future Research}

Future research is needed in multiple areas to complete the gaps left by this research and other studies on goal setting. First, research is needed on goal content analysis that directly interviews students about goals, allowing for clarification and follow-up questions. Future studies might also examine goals reported by students with disabilities compared with goals reported by students without disabilities. Moreover, the type or label of disability may affect the goals students provide and should be examined in future analyses that continue to follow students and monitor their goals. As Miller and Kelley (1994) found, commitment to goals may change over time, leading to new or modified goals. Research is needed on the process students use to set goals and also on goal completion.

This particular study is preliminary in nature and therefore leads to more investigation. There were several instances in which statistical significance was not found but interesting trends emerged. One example is in terms of the lack of statistical significance between the two ability level groups. More research is needed to determine if those results are specific to the population of this study or if a difference may exist in other samples of students naming goals. However, the data show that students of all ability groups are able to state goals and hopefully benefit from the process of goal setting.

\section{Implications for Practice}

Educators should consider variations in goal content for students as they progress through school. Special and general education teachers may want to work with students with and without disabilities and provide both guidance and assistance in helping students identify, monitor, and attain goals. Educators are in an excellent position to aid students in increasing self-determination through goal setting and attainment. If students with lower ability levels tend to report more nonacademic goals, educators may suggest setting more academic goals to increase possible success in this area. Similarly, educators may want to encourage middle school students to set more long-term goals to promote thinking about transition and other postsecondary outcomes. Additionally, educators may also want to work with students on the types of goals students set. For example, social goals can play an important role in the transition of students in terms of having appropriate interactions with others. These are often the types of goals that can aid in an individual's ability to acquire and maintain employment. In the current study, teachers tended to report more social goals than did students, possibly indicating students' inability to see such goals as important. Another example would be expanding a high school curriculum to include setting long-term goals upon exit from secondary or postsecondary educational settings. The importance of goal setting and monitoring must be explained to all students, so students can continue to consider and set goals for their desired achievements even after exiting secondary education.

Next, teachers need to provide direct instruction in setting goals. Goal setting is one strategy that needs to be a part of the curriculum for all students, not just for students with disabilities. By working on setting and attaining goals, students learn valuable skills, learn to work to goal completion, practice self-evaluation abilities, and understand that they must be involved to influence goal attainment. Goals that are overtly stated can support a student to put into place planning, achievement, and completion of goal-related activities. 
In addition, parents can be recruited to be a part of the goal-setting and attainment process. Often goals involve work completion or attainment of study time that might not all take place at school. Involving parents may strengthen the application of goal setting by providing another environment in which to practice and spend time on goals.

Finally, students in middle school are clearly able to set goals and should be highly encouraged to use strategies for goal setting and attainment in not only academic but also behavioral and social areas. The same emphasis on goal setting can be used with students at the high school level, including transition outcomes.

\section{Declaration of Conflicting Interests}

The author(s) declared no potential conflicts of interests with respect to the authorship and/or publication of this article.

\section{Financial Disclosure/Funding}

The research reported here was supported by the Department of Education NIDRR Grant 84.133A to the University of Kansas. The opinions expressed are those of the authors and do not represent views of the U.S. Department of Education.

\section{References}

Agran, M., Blanchard, C., \& Wehmeyer, M. L. (2000). Promoting transition goals and self-determination through studentdirected learning: The Self-Determined Learning Model of Instruction. Education and Training in Mental Retardation and Developmental Disabilities, 35, 351-364.

Agran, M., \& Wehmeyer, M. L. (2008). Person-centered career planning. In F. R. Rusch (Ed.), Beyond high school: Preparing adolescents for tomorrow's challenges (2nd ed., pp. 56-77). Upper Saddle River, NJ: Pearson.

Berk, L. E. (1999). Infants, children, and adolescents (3rd ed.). Boston: Allyn \& Bacon.

Bong, M. (2001). Between- and within-domain relations of academic motivation among middle and high school students: Self-efficacy, task-value and achievement goals. Journal of Educational Psychology, 93, 23-34.

Carter, E. W., Lane, K. L., Pierson, M. R., \& Glaeser, B. (2006). Self-determination skills and opportunities of transition-age youth with emotional disturbance and learning disabilities. Retrieved July 13, 2008, from http://www.redorbit.com/news/ education/454054/selfdetermination_skills_and_opportunities _of_transitionage_youth_with_emotional_disturbance/

Copeland, S. R., \& Hughes, C. (2002). Effects of goal setting on task performance of persons with mental retardation. Education and Training in Mental Retardation and Developmental Disabilities, 37, 40-54.

Fuchs, L. S., Fuchs, D., Karns, K., Hamlett, C. L., Katzaroff, M., \& Dutka, S. (1997). Effects of task-focused goals on lowachieving students with and without learning disabilities. American Educational Research Journal, 34, 513-543.
Graham, S., MacArthur, C., Schwartz, S., \& Page-Voth, V. (1992). Improving the compositions of students with learning disabilities using a strategy involving product and process goal setting. Exceptional Children, 58, 322-335.

Johnson, L. J., \& LaMontagne, M. J. (1993). Using content analysis to examine the verbal or written communication of stakeholders within early intervention. Journal of Early Intervention, 17, 73-79.

Konrad, M., Fowler, C. H., Walker, A. R., Test, D. W., \& Wood, W. M. (2007). Effects of self-determination interventions on the academic skills of students with learning disabilities. Journal of Learning Disabilities Quarterly, 30, 89-113.

Landis, J. R., \& Koch, G. G. (1977). The measurement of observer agreement for categorical data. Biometrics, 33, 159-174.

Lee, Y., Wehmeyer, M., Palmer, S., Williams-Diehm, K., Davies, D., $\&$ Stock, S. (in press). The effect of student-directed transition planning using a computer-based reading support program on the self-determination of students with disabilities. Journal of Special Education.

Leondari, A., \& Gonida, E. (2007). Predicting academic selfhandicapping in different age groups: The role of personal achievement goals and social goals. British Journal of Educational Psychology, 77, 595-611.

Locke, E. A., \& Latham, G. P. (2002). Building a practically useful theory of goal setting and task motivation: A 35-year odyssey. American Psychologist, 57, 705-717.

McEwin, C. K., Dickinson, T. S., Jenkins, D. M. (1996). America's middle schools: Practices and progress: A 25-year perspective. Columbus, OH: National Middle School Association.

Miller, D. L., \& Kelley, M. L. (1994). The use of goal setting and contingency contracting for improving children's homework performance. Journal of Applied Behavior Analysis, 27, 73-84.

Mithaug, D. E., Mithaug, D. K., Agran, M., Martin, J. E., \& Wehmeyer, M. L. (Eds.). (2003). Self-determined learning theory: Construction, verification, and evaluation. Mahwah, NJ: Lawrence Erlbaum.

Page-Voth, V., \& Graham, S. (1999). Effects of goal setting and strategy use on the writing performance and self-efficacy of students with writing and learning problems. Journal of Educational Psychology, 91, 230-240.

Palmer, S. B., Wehmeyer, M. L., Gipson, K., \& Agran, M. (2004). Promoting access to the general curriculum by teaching selfdetermination. Exceptional Children, 70, 427-439.

Patton, M. Q. (1990). Qualitative evaluation and research methods. Newbury Park, CA: Sage.

Pellegrini, A. (1996). Observing children in their natural worlds: A methodological primer. Mahwah, NJ: Lawrence Erlbaum.

Sands, D., \& Doll, E. (2005). Teaching goal setting and decision making to students with developmental disabilities. In M. L. Wehmeyer \& M. Agran (Eds.), Mental Retardation and intellectual disabilities: Teaching students using innovative and research-based strategies (pp. 273-296). Washington, DC: American Association on Mental Retardation. 
Shilts, M. K., Horowitz, M., \& Townsend, M. S. (2004). An innovative approach to goal setting for adolescents: Guided goal setting. Journal of Nutrition Education and Behavior, 36, 155-156.

Shogren, K. A., Wehmeyer, M. L., Palmer, S. B., Soukup, J. H., Little, T. D., Garner, N., \& Lawrence, M. (2008). Understanding the construct of self-determination: Examining the relationship between the Arc's Self-Determination Scale and the American Institutes for Research Self-Determination Scale. Assessment for Effective Intervention, 33, 94-107.

Urdan, T. C., \& Maehr, M. L. (1995). Beyond a two-goal theory of motivation and achievement: A case for social goals. Review of Educational Research, 65, 213-243.

Wehmeyer, M. L. (2006). Self-determination and individuals with severe disabilities: Reexamining meanings and misinterpretations. Research and Practice in Severe Disabilities, 30, 113-120.

Wehmeyer, M. L., \& Agran, M. (Eds.). (2005). Mental retardation and intellectual disabilities: Teaching students using innovative and research-based strategies. Boston: Pearson.

Wehmeyer, M. L. Agran, M., \& Hughes, C. (1998). Teaching selfdetermination to students with disabilities: Basic skills for successful transition. Baltimore: Brookes.

Wehmeyer, M. L., Agran, M., Hughes, C., Martin, J. E., Mithaug, D. E., $\&$ Palmer, S. B. (2007). Promoting self-determination in students with developmental disabilities. New York: Guilford.

Wehmeyer, M. L., \& Bolding, N. (1999). Self-determination across living and working environments: A matched-samples study of adults with mental retardation. Mental Retardation, 37, 353-363.

Wehmeyer, M. L., Palmer, S. B., Agran, M., Mithaug, D. E., \& Martin, J. (2000). Promoting causal agency: The self-determined learning model of instruction. Exceptional Children, 66, 439-453.
Wehmeyer, M. L., Palmer, S., Shogren, K., Williams-Diehm, K., \& Soukup, J. (2010). Establishing a causal relationship between interventions to promote self-determination and enhanced student self-determination. Unpublished manuscript.

Wolman, J., Campeau, P., Dubois, P., Mithaug, D., \& Stolarski, V. (1994 ). AIR Self-Determination Scale and user guide. Palo Alto, CA: American Institute for Research.

Zimmerman, B. J., \& Kitsantas, A. (1997). Developmental phases in self-regulation: Shifting from process goals to outcome goals. Journal of Educational Psychology, 89, 29-36.

\section{Bios}

Kendra Williams-Diehm, $\mathrm{PhD}$, is an assistant professor in the Educational Psychology Department at the University of Oklahoma. Her current interests include transition and self-determination for students with moderate to severe disabilities and from diverse cultural backgrounds.

Susan Palmer, $\mathrm{PhD}$, is an associate research professor in the Beach Center on Disability at the University of Kansas. Dr. Palmer's interests include self-determination and access to the general curriculum for students with disabilities.

Youngsun Lee, $\mathrm{PhD}$, is full-time lecturer of special education in the Department of Education at Inha University. Her research interests include self-determination, transition planning, and technology use for secondary students with disabilities.

Heather Schroer, EdS, is a practicing school psychologist in the Olathe School District in Olathe, Kansas. 